\title{
Performance of Porous Asphalt Mixture Containing Seashell as Aggregate Replacement
}

\author{
N. Liew*, R.P Jaya and K.A Masri \\ Department of Civil Engineering, College of Engineering, Universiti Malaysia Pahang, 26300 Pahang, Malaysia
}

ABSTRACT - Porous asphalt pavement is mainly used for parking lots which able to let water to drain through the pavement surface into a stone recharge bed and infiltrate into soils under the pavement. This study is to investigate the performance of seashell in porous asphalt and determine the image analysis. The seashell used in this study is cockle shell. The strength of seashell was determined through the Aggregate Impact Value Test (AIV) and Aggregate Crushing Value Test (ACV). The grade of bitumen used was grade 60/70. The porous asphalt volumetric properties was determined through Marshall Stablity Test. The permeability coefficient of sample that contain seashell as aggregate replacement was determined through Permeability Test. Generally, the results shows that the seashell's percentage loss (AIV and ACV) is suitable use for porous asphalt mixture, where the percentage of loss for AIV and ACV was $27.84 \%$ and $7.65 \%$ respectively. Based on the Marshall Test, porous asphalt that containing seashell as aggregate replacement shows a different result, where it had lower stability value and it can increase the bulk density of porous asphalt mixture. Furthermore, the permeability coefficient also increase. The surface of seashell able to bond with bitumen. Lastly, the trend of VFA and VTM value is effected by the surface and position of seashell in the porous asphalt sample.

ARTICLE HISTORY

Received: $13^{\text {th }}$ March 2021

Revised: $8^{\text {th }}$ April 2021

Accepted: $3^{\text {rd }}$ May 2021

\section{KEYWORDS}

Porous Asphalt

Seashell

Cockle Shell

Image Processing

ImageJ Software

\section{INTRODUCTION}

Aggregate is the most common material use for building construction and pavement construction. The process of aggregate extraction, such as mined from the earth, pit dugout, or quarries blasted out, has negatively impacted our environment. Those bad impacts on our environment are vibration, noise, and dust caused by blasting, groundwater degradation, and landscape changes. UNEP Global Environment Alert Service 2014 stated that over 40 billion tonnes of aggregate had been consumed in the world, and between $64 \%$ to $75 \%$ of the aggregate is used for concrete in construction [1]. Thus, the consumption of aggregate will cause an environmental problem due to the decreasing of natural earth resources.

A shellfish have a protective shell which it always been called as a seashell. When human consumed shellfishes as a food, the seashell will have some or no commercial value; thus, it always been discarded. All the untreated seashell waste will create unsightly appearance and unpleasant smell to this environment. High quantities of seashell waste can lead to a serious environmental problem. This serious environmental problem is due to, the microbial decomposition of salt in untreated seashell waste will turn into gases such as amines, hydrogen sulphide and ammonia. Thus, seashell can be considered as a potential waste material in this world, where it comes from many types, such as cockle shell, mussel shell, periwinkle shell, oyster shell and mussel shell. Seashell waste is an ordinary waste in countless countries, but China is the world's largest producer of shellfish, where the seashell waste produced by China is about 10 million tonnes; followed by Galicia, northern Spain is the second-largest in producing shellfish, where the seashell waste produced by Galicia is about 25,000 tonnes [2].

From previous studies, it was shown that seashell waste could use as an aggregate replacement in concrete. Calcium carbonate is the main component in a seashell; therefore, seashell has the same structure as limestone, which it is inactive in concrete [2]. Unfortunately, seashell waste still contains considerable amounts of organic matter, sulphates and chlorides that will make the seashell aggregate concrete has lower durability and lower strength compared to the natural aggregate concrete [3]. Furthermore, seashell waste was logically to replace seashell waste as an aggregate in porous asphalt mixture to reduce the consumption of natural earth resources. By referring to the previous studies, seashell waste was used as fine aggregate in hot mix asphalt. As the seashell size is smaller than $1 \mathrm{~mm}$, air voids in the asphalt mixture can be reduced, the stability of the asphalt mixture can be increased, and resistance to stripping can be increased. On the other hand, seashell can be categorized as a good binder in asphalt mixture. However, seashell aggregate asphalt needs more asphalt content as compared to natural aggregate [4].

In the 1960s, porous asphalt pavement is mainly developed to reduce traffic noise and improve road surface to drive safe. Open-Graded Friction Course (OGFC) in the United States stated that porous asphalt pavement with high air voids content, which the air voids content is higher than $15 \%$, anti-slip performance on the pavement could be improved [5].The porous asphalt pavement technique was promoted to Japan and China in the 1980s. Now, porous asphalt 
designs to reduce stormwater runoff, where it allows water to move through the asphalt layer. Porous asphalt pavement is mainly used for parking lots which able to let water to drain through the pavement surface into a stone recharge bed and infiltrate into soils under the pavement.

The advance of imaging technologies had enabled the use of software in many research; one of the popular image processing software is ImageJ. Image that calibrated from ImageJ clearly show the particle size and differentiate between different compenent in sample (bitumen and aggregate). Thus, the interaction between seashell and bitumen was analysed based on ImageJ software.

\section{MATERIALS AND METHOD}

\section{Binder, Aggregate and Gradation}

In order to prepare a porous asphalt sample, the grade of bitumen used in this research was bitumen grade 60/70. Bitumen grade $60 / 70$ is the range of bitumen that fall within the range of 60 to 70 at standard test condition of penetration value which generally used as a paving grade. Bitumen grade 60/70 has a thermoplastic property which caused the material to soften in high temperature and hardened in low temperature. The aggregate used in this research is granite aggregate. The porous asphalt aggregate grading is presented in Table 1.

Table 1. Aggregate Grading for Porous Asphalt.

\begin{tabular}{cc}
\hline Sieve Size $(\mathrm{mm})$ & Percentage Passing $(\%)$ \\
\hline 20 & 100 \\
14 & $85-100$ \\
10 & $55-57$ \\
5 & $10-25$ \\
2.36 & $5-10$ \\
0.075 & $2-4$ \\
\hline
\end{tabular}

\section{Cockle Shell as Aggregate Replacement}

The seashell waste was collected from the nearby seafood restaurant, which needs to be throw. To ensure the good quality and physical properties of sample, the seashell waste need to be rinsed and submerge in hot water at temperature $100^{\circ} \mathrm{C}$ for at least 10 minutes, as shown in Figure 1 . After that, repeat this step again, to make sure the seashell is completely clean. Next, put the seashell into the oven for 24 hours or dry under the sun for 24 hours, to make sure there is no water content in the seashell, as shown in Figure 2. After that, sieve analysis is a must to ensure the size of seashell is standardize by according to the porous asphalt aggregate grading. The seashell size for replacement is size $14 \mathrm{~mm}$.

The strength of seashell can be determined through the Aggregate Impact Value Test (AIV) and Aggregate Crushing Value Test (ACV). Aggregate Impact Value Test (AIV) able determine the aggregate impact value of seashell in the laboratory, and through Aggregate Impact Value Test, the satisfactory of aggregate (seashell) in road construction also can be assessed. The next test is the Aggregate Crushing Value Test (ACV), where the aggregate (seashell) crushing value can be determined.

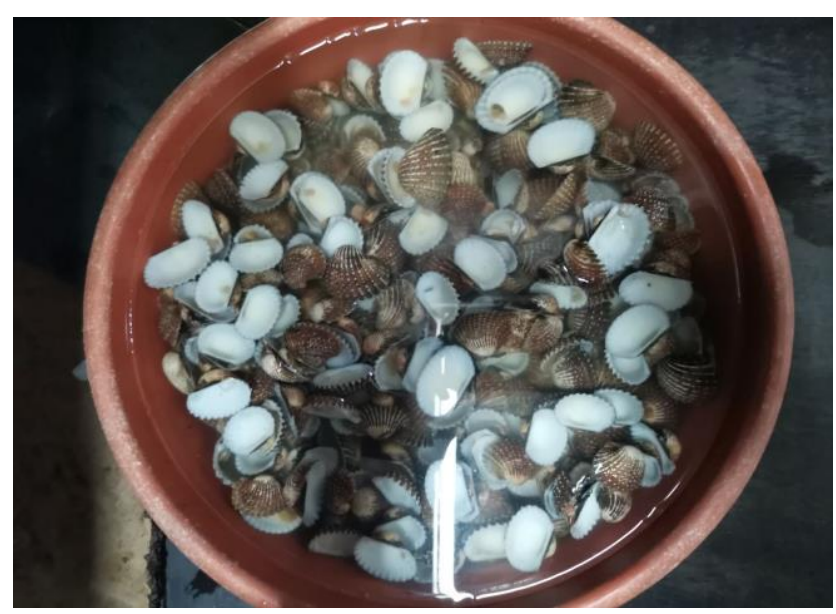

Figure 1. Cockle shell submerge in hot water at temperature $100^{\circ} \mathrm{C}$ 


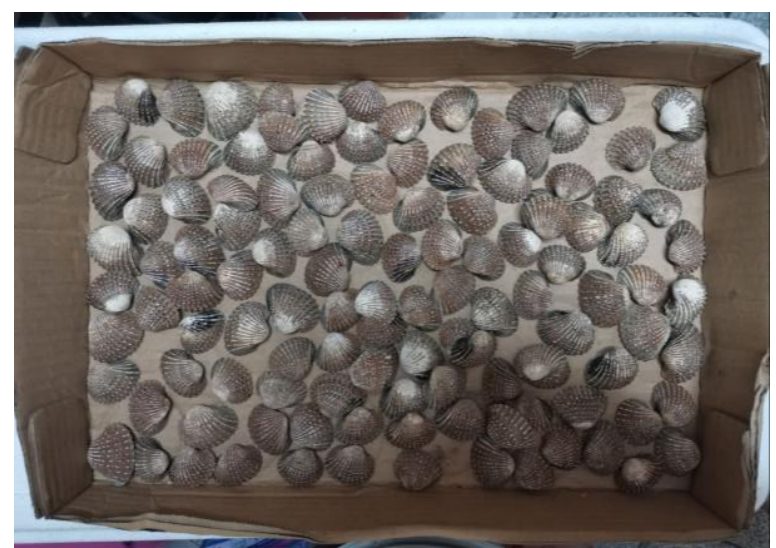

Figure 2. Dried cockle shell

\section{Marshall Mixed Design and Volumetric Properties}

Marshall Mixed Design is a method to prepare a standard specimen of porous asphalt for the determination of stability and flow in the Marshall apparatus. A few of test needed to carry out for the porous asphalt mix, such as void analysis and density test [6].

On the other hand, there were some basic method can be considered in Marshall Mixed Design, such as aggregate selection, asphalt binder selection, sample preparation, stability determination, calculation of voids and density, and optimum asphalt binder content selection.

It was important to determine the physical properties of aggregate during the selection of aggregate. Gradation and sizing of aggregate also important, thus, sieve analysis need to be conducted. Next, for the binder selection, this study required bitumen grade 60/70. The compaction for each sample was carried out in 50 blows.

The value of stability, flow, density, Percentage Air Voids (VMA), Voids Filled with Asphalt (VFA), and Voids in Total Mix (VTM) can be analysed through Marshall Mix Design Test. The percentages of aggregate replacement in the sample are $10 \%, 20 \%, 30 \%, 40 \%$ and $50 \%$, and each percentage will have 2 samples, this is to determine the average value of every sample.

\section{Permeability Test}

The permeability coefficient of porous asphalt sample that contain seashell as aggregate replacement can be tested through Permeability Test. The coefficient permeability can be calculated using Equation 1, where $k$ (permeability coefficient, $\mathrm{cm} / \mathrm{s}$ ), $A$ (area of the sample, $\mathrm{cm}^{2}$ ), $a$ (area of the standpipe, $\mathrm{cm}^{2}$ ), $l$ (height of sample, $\mathrm{cm}$ ), $h_{l}$ (initial water height that above sample, $\mathrm{cm}$ ), $h_{2}$ (final water height that above sample, $\mathrm{cm}$ ), and $t$ (time taken for water to fall from $h_{1}$ to $h_{2}, \mathrm{~s}$ ) [7]. The percentages of aggregate replacement in the sample are $10 \%, 20 \%, 30 \%, 40 \%$ and $50 \%$ accordingly.

$$
k=\frac{a l}{A t} \ln \left(\frac{h_{1}}{h_{2}}\right)
$$

\section{Image Processing}

The sample was cut in half, and scanned the surface of cut part by using a printer, as shown in Figure 3. The image of cut sample was analysed using ImageJ, an image processing software. Where, it able to analyse the particle that show in an image, measure the size and area of the particle that show in an image. ImageJ also able to calibrate an image, such as calibrated optical density step tablet and radioactive isotope standards. Surface Plot also can be considered as a feature in ImageJ, where it displays a three dimensional graph in grayscale or pseudo colour. The binding between seashell and bitumen also can be analysis through ImageJ. 

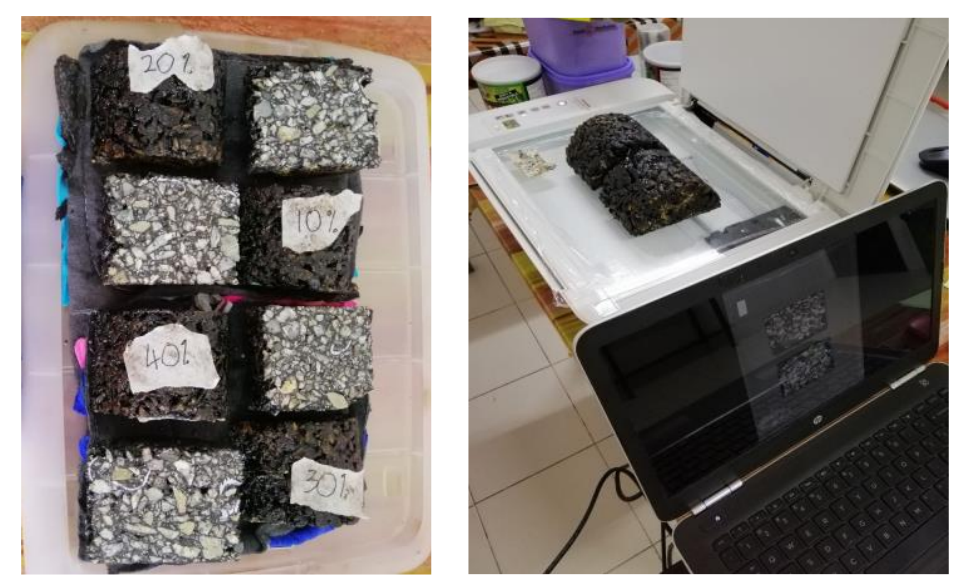

Figure 3. Cut sample and surface of cut part by using a printer

\section{RESULT AND DISCUSSION}

\section{Aggregate Impact Value Test}

Table 2 shows the result of AIV for seashell and aggregate. The percentage of loss in AIV is between $20 \%$ to $30 \%$ [8]. Table 2 shows that the percentage of loss for seashell that passed through the sieve size of $2.36 \mathrm{~mm}$ was $27.84 \%$, where it falls within the range of $20 \%$ to $30 \%$. Based on Table 3, it is satisfactorily for road surfacing, and it is suitable to use for porous asphalt.

Table 2. Aggregate Impact Value Test Result

\begin{tabular}{|c|c|c|c|c|c|}
\hline \multirow{2}{*}{ Sample } & \multirow{2}{*}{ AggregateSize } & \multicolumn{2}{|c|}{ Weight of Crushed Aggregate (g) } & \multirow{2}{*}{ \% Loss } \\
\cline { 3 - 5 } & & Before (M1) & After (M2) & Loss (M3) & \\
\hline Aggregate & $14 \mathrm{~mm}-10 \mathrm{~mm}$ & 290.82 & 224.92 & 64.28 & 22.10 \\
\hline Seashell & $20 \mathrm{~mm}-14 \mathrm{~mm}$ & 143.67 & 100.00 & 40.00 & 27.84 \\
\hline
\end{tabular}

Table 3. Classification of aggregates using Aggregate Impact Values

\begin{tabular}{cc}
\hline $\begin{array}{c}\text { Aggregate Impact Value } \\
(\%)\end{array}$ & Description \\
\hline$<10 \%$ & Exceptionally Strong \\
$10 \%-20 \%$ & Strong \\
$20 \%-30 \%$ & Satisfactory for road \\
surfacing \\
$>35 \%$ & Weak for road surfacing \\
\hline
\end{tabular}

\section{Aggregate Crushing Value Test}

Table 4 shows the result of ACV for seashell and aggregate. The percentage of loss in ACV is less than or equal to $25 \%$ [8]. Table 4 shows that the percentage of loss for seashell that passed through the sieve size of $2.36 \mathrm{~mm}$ was $7.65 \%$, where it is less than $25 \%$. Thus, it is suitable to use for porous asphalt.

Table 4. Aggregate Crushing Value Test Result

\begin{tabular}{|c|c|c|c|c|c|}
\hline \multirow{2}{*}{ Sample } & \multirow{2}{*}{ AggregateSize } & \multicolumn{2}{|c|}{ Weight of Crushed Aggregate (g) } & \multirow{2}{*}{ \% Loss } \\
\cline { 3 - 5 } & & Before (M1) & After (M2) & Loss (M3) & \\
\hline Aggregate & $14 \mathrm{~mm}-10 \mathrm{~mm}$ & 2637.82 & 2188.82 & 449.45 & 17.03 \\
\hline Seashell & $20 \mathrm{~mm}-14 \mathrm{~mm}$ & 1175.71 & 1090.00 & 90.00 & 7.65 \\
\hline
\end{tabular}




\section{Bulk Density}

Figure 4 shows the bulk density of porous asphalt at different percentage of seashell. As compared to the porous asphalt sample that containing seashell as aggregate replacement, the bulk density of conventional porous asphalt sample is the lowest. This results clearly shows that, the replacement of seashell in porous asphalt sample can increase the bulk density of the sample, where the bulk density for all porous asphalt sample that containing seashell as aggregate replacement is more than $2 \mathrm{~g} / \mathrm{cm}^{3}$, however the bulk density of conventional porous asphalt sample is 1.86 $\mathrm{g} / \mathrm{cm}^{3}$.

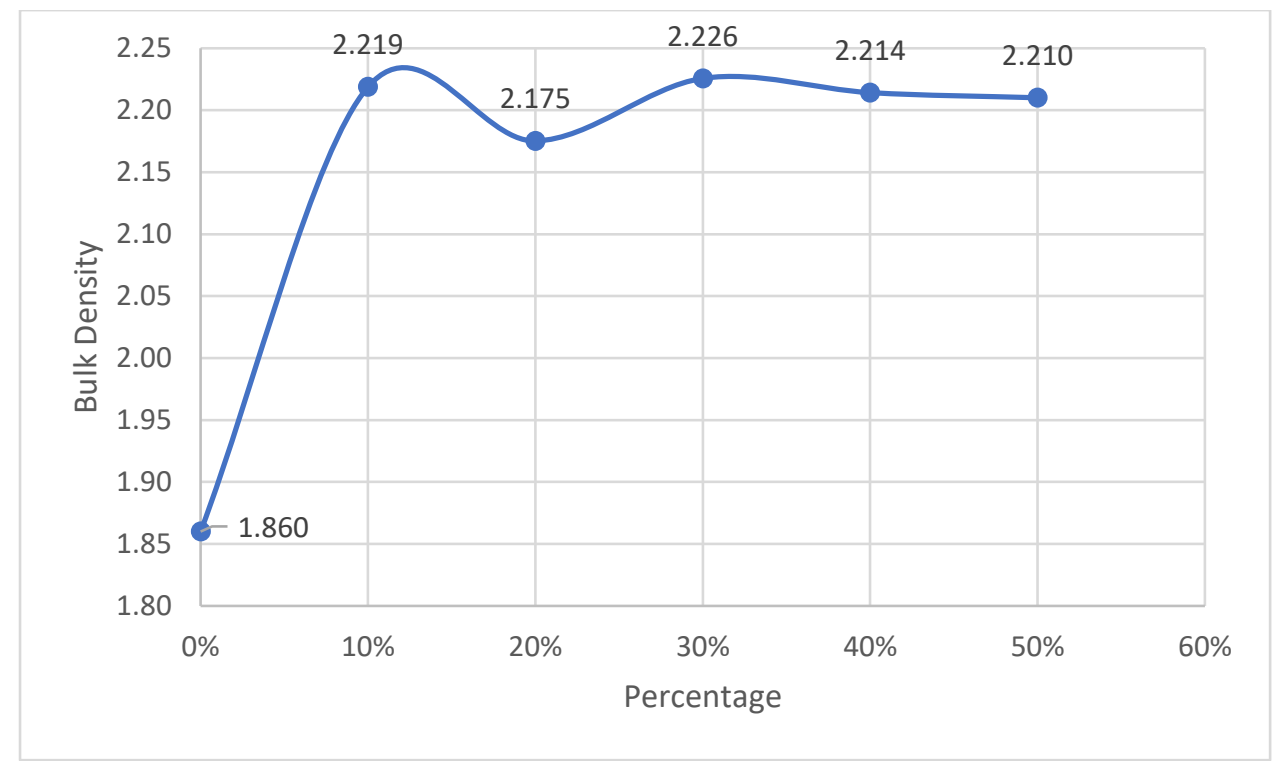

Figure 4. Bulk Density at different percentage of seashell

\section{Voids Filled with Asphalt}

VFA can be considered as the void ratio in porous asphalt sample. Figure 5 shows the percentage of VFA of porous asphalt sample at different percentage of seashell. As shown in Figure 5, the replacement of seashell in porous asphalt sample decreases the percentage of VFA. This is due to the curved shape of seashell, where the small aggregate and filler can trap in the curved blank space. The curved shape of seashell and the position of seashell in porous asphalt sample, cause the trend of VFA percentage is not consistent as shown in Figure 5.

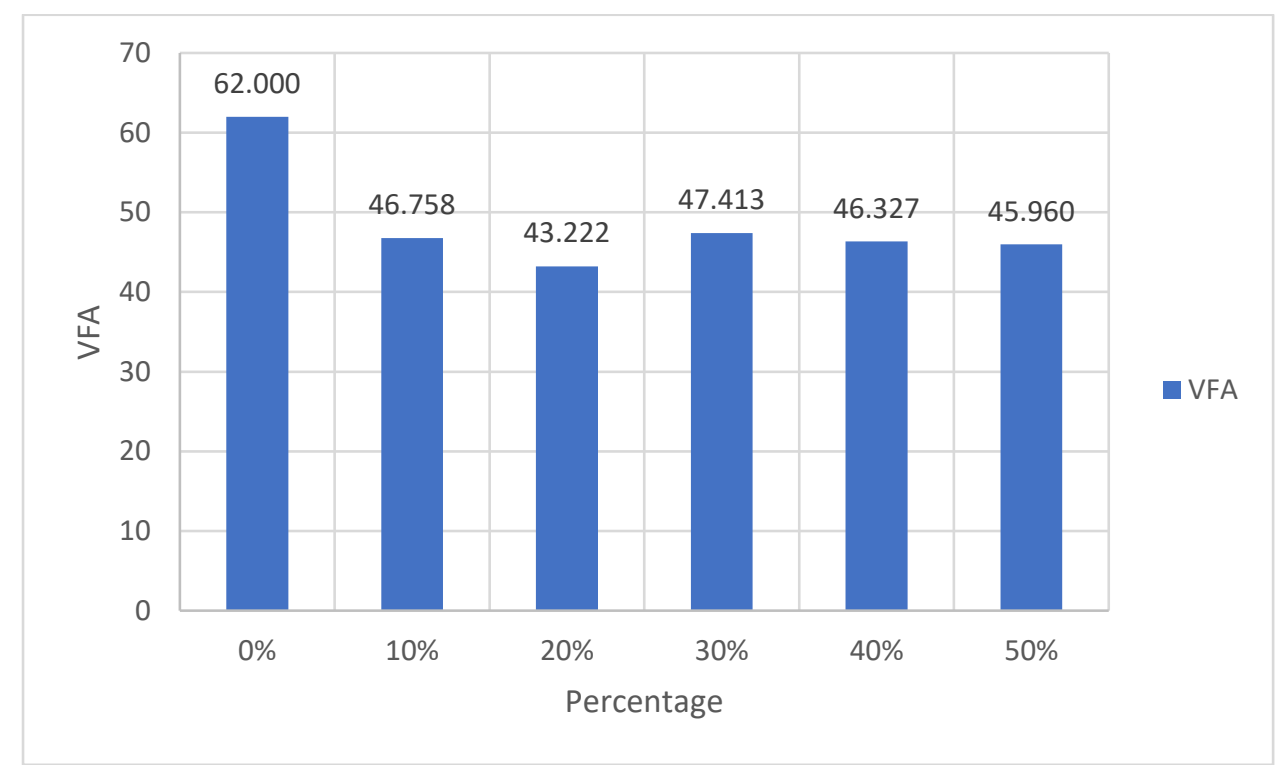

Figure 5. VFA at different percentage of seashell 


\section{Voids in Total Mix (VTM)}

Figure 6 shows the VTM of porous asphalt at different percentage of seashell. Based on Figure 6, the conventional porous asphalt sample, $10 \%, 30 \%, 40 \%$, and $50 \%$ of seashell replacement porous asphalt sample the percentage of VTM is around $12 \%$. Thus, this shows that the replacement of seashell in porous asphalt sample can get nearly the same percentage of VTM with a conventional porous asphalt sample. However, from Figure 6, there is a sharply rise for the $20 \%$ of seashell replacement porous asphalt sample, where it is the highest percentage of VTM among the other sample. This is due to the position of seashell in porous asphalt sample is different from other sample $(10 \%, 30 \%, 40 \%$, and $50 \%$ of seashell replacement porous asphalt sample).

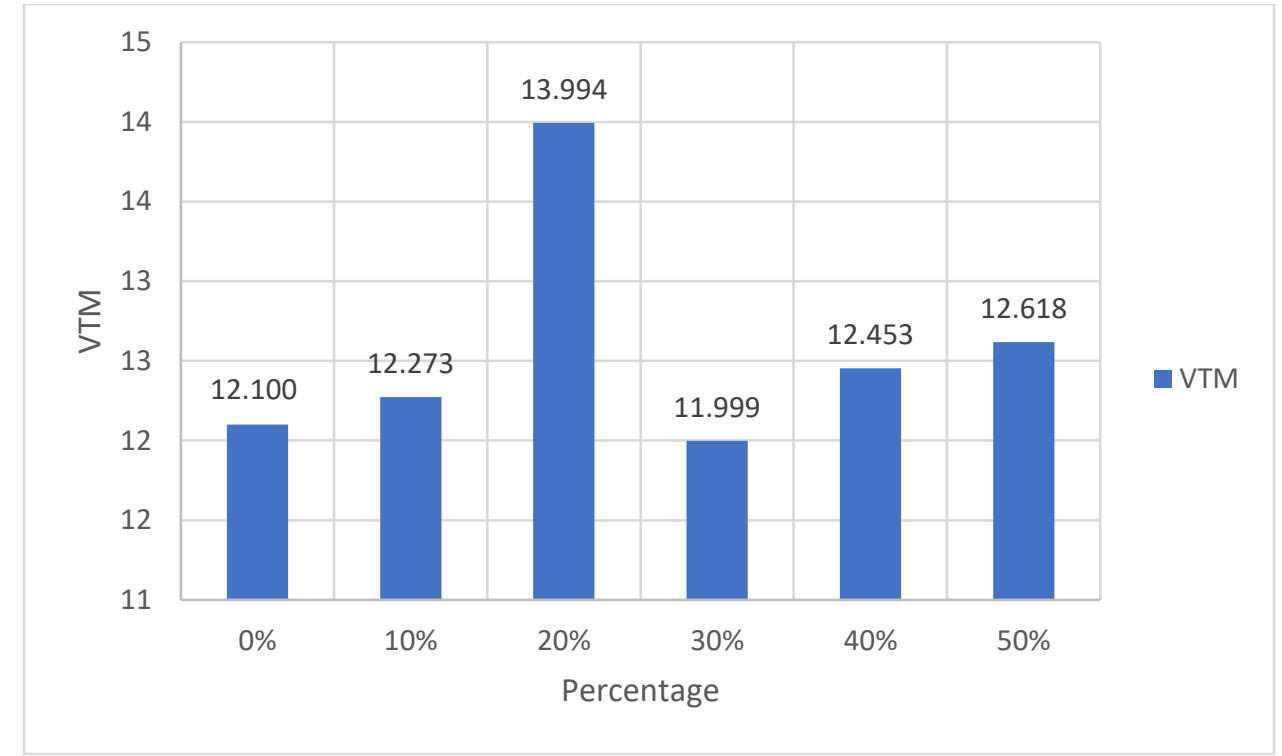

Figure 6. VTM at different percentage of seashell

\section{Density and Stability}

Figure 7 shows the relationship between density and stability of porous asphalt at different percentage of seashell, where it clearly show that the replacement of seashell in porous asphalt sample decreases the stability of porous asphalt sample. This lower strength of seashell porous asphalt sample is caused by the low specific gravity [21]. However, the replacement of seashell in porous asphalt sample increase the density of porous asphalt sample. As stated in Figure 7 , the stability of porous asphalt will higher than the density of porous asphalt. However, the density and stability for $10 \%$ of seashell replacement porous asphalt had the nearly same value, and this obviously shows that the trend of stability is unstable due to the replacement of seashell in porous asphalt.

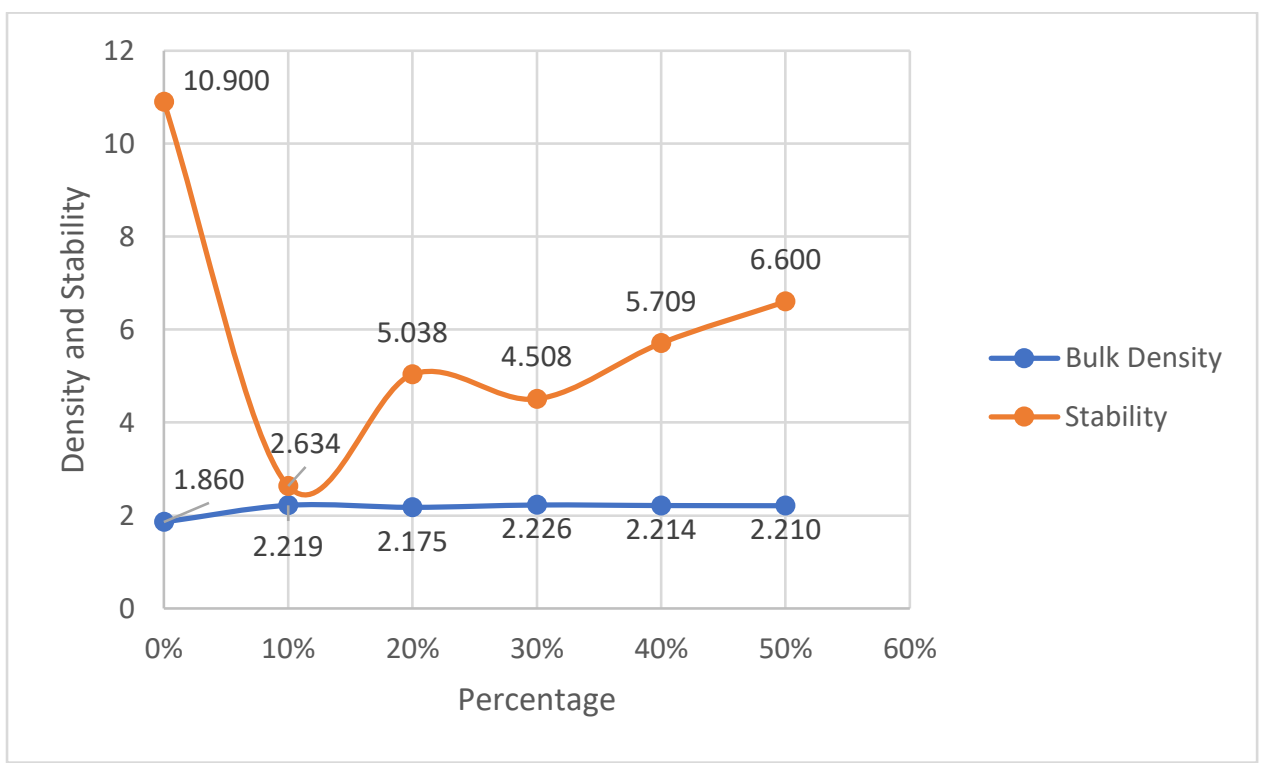

Figure 7. Relationship between Density and Stability at different percentage of seashell 


\section{Stability and Flow}

The relationship between stability and flow of porous asphalt at different percentage of seashell is shown in Figure 8. By referring to Figure 8, the stability of conventional porous asphalt sample is higher than the flow of conventional porous asphalt sample. However, the replacement of seashell in porous asphalt sample cause the trend of both stability and flow unstable. Also, the replacement of seashell in porous asphalt sample cause the stability lower than the flow. The unstable flow for the sample that containing seashell as aggregate replacement is effected by the concentration of the bitumen.

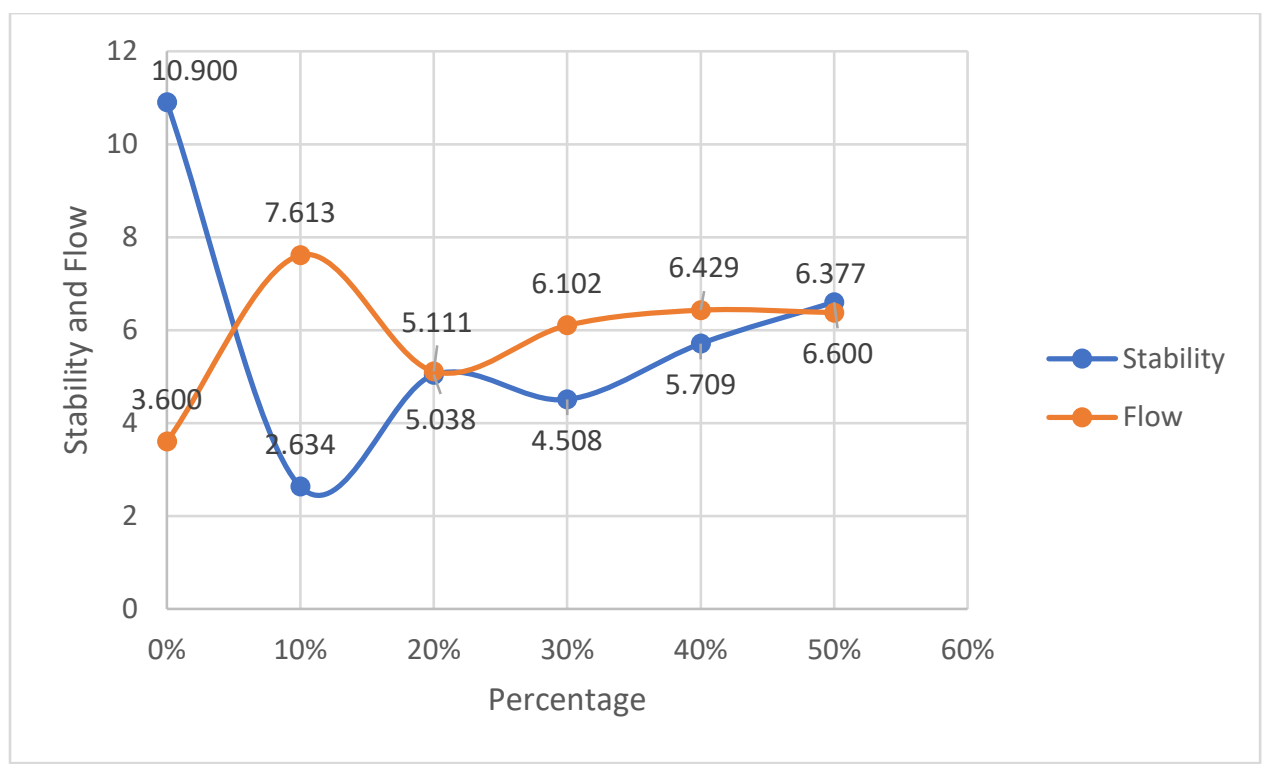

Figure 8. Relationship between Stability and Flow at different percentage of seashell

\section{Permeability Test}

The permeability coefficient of porous asphalt mixture is as shown in Figure 9. The conventional porous asphalt sample had the lowest permeability coefficient as compared to the other sample that containing seashell as aggregate replacement. The trend as stated in Figure 9 clearly show that the replacement of seashell in porous asphalt sample increase the permeability coefficient. From Figure 9, the seashell replacement percentage is increasing, the permeability coefficient is decreasing; however, there is a sudden drop at $30 \%$ of seashell replacement porous asphalt. The sudden drop might due to the placement of the seashell inside the porous asphalt sample is facing up; thus it will took a longer time for water to flow out, as compared to the others sample.

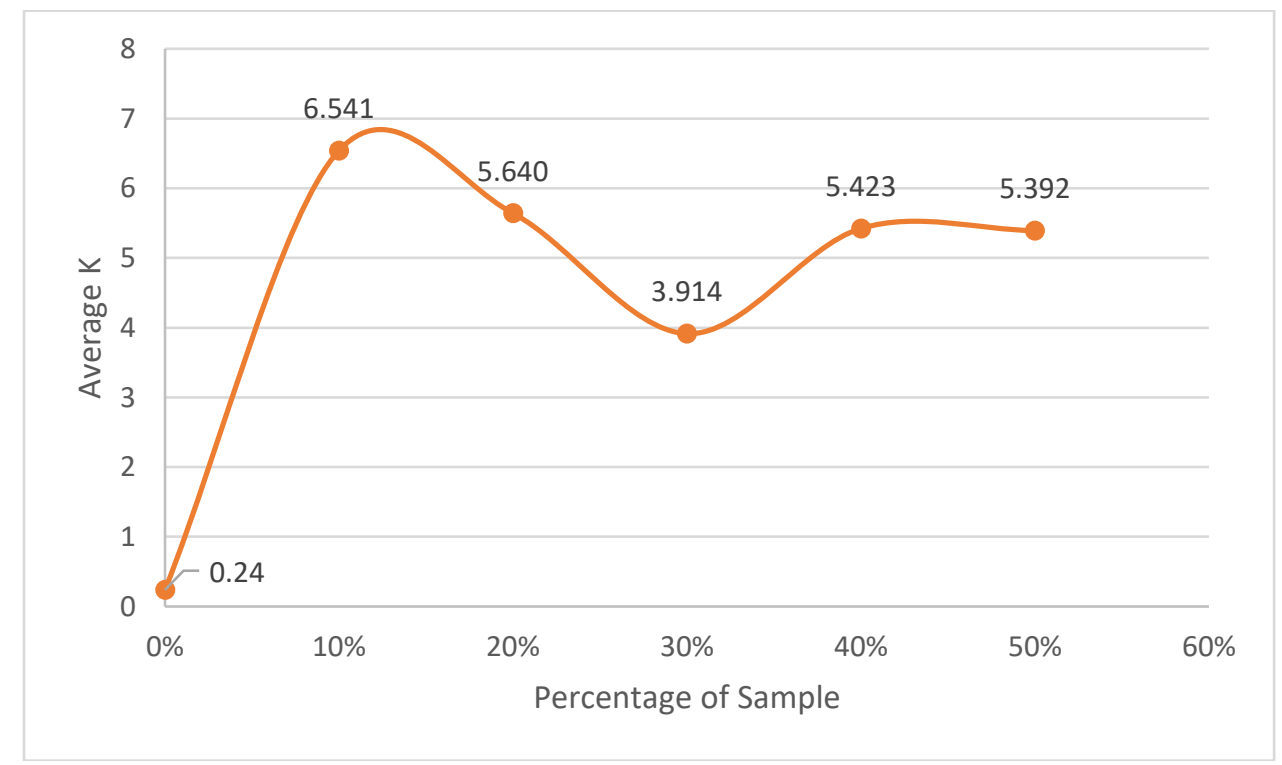

Figure 9. Permeability Coefficient at different percentage of seashell 


\section{Image Analysis}

The different between natural aggregate and seashell that contained in porous asphalt sample is labeled in Figure 10. The type of image for porous asphalt sample that containing 50\% of seashell as aggregate replacement is shown in Figure 11. Ellipses Image had shown the best fit ellipse for each measured particles in porous asphalt sample. The difference between bitumen content and aggregate size is clearly displayed in Outline Image, where the red colour represents bitumen, and the white colour with different shape represents aggregate with different size and shape. According to Figure 11, the binding between seashell and bitument is good, as it does not show a big gap between seashell and bitumen. The good binding between seashell and bitument can be caused by the shape and surface of seashell. Furthermore, due to the curved shape of seashell, it can clearly see that the small aggregate and filler filled in the blank space of the seashell.

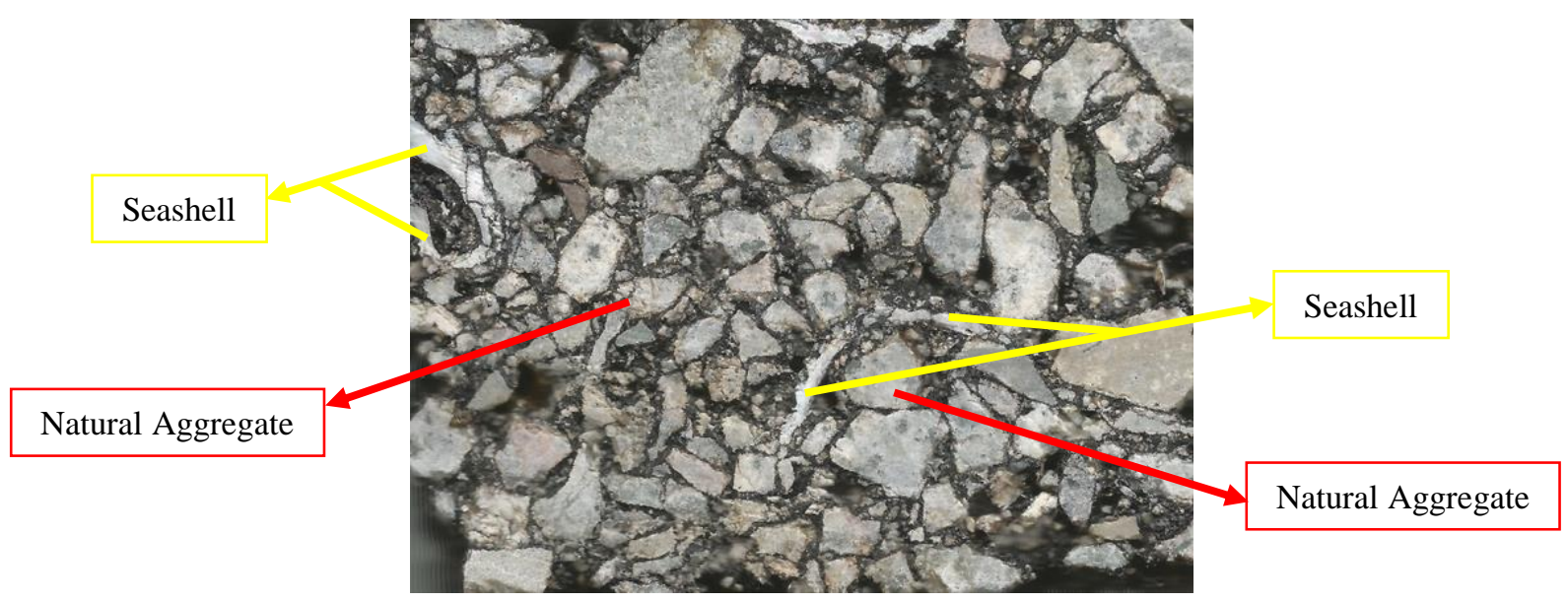

Figure 10. Label to differentiate between natural aggregate and seashell

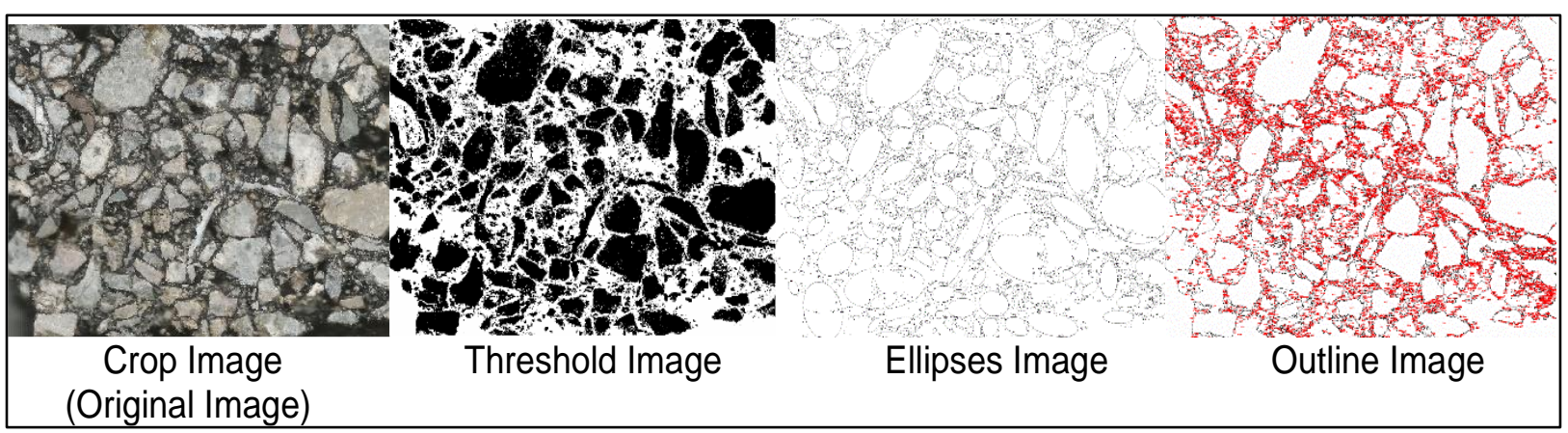

Figure 11. Images processed from ImageJ software

Figure 12 shows the surface plot for porous asphalt sample that containing 50\% seashell as aggregate replacement. The surface plot displayed a three-dimensional of porous asphalt sample containing seashell as aggregate replacement. The sags and crests surface as shown in Figure 11 clearly differentiate the height between bitumen and aggregate, also the different size of area represents the irregular surface of aggregate and seashell that containing in the sample. By referring to Figure 12, the height of cut porous asphalt sample that containing $50 \%$ seashell as aggregate replacement was $255 \mathrm{~mm}$, the length and width of it was $71.8 \mathrm{~mm}$ and $98.1 \mathrm{~mm}$ respectively. 


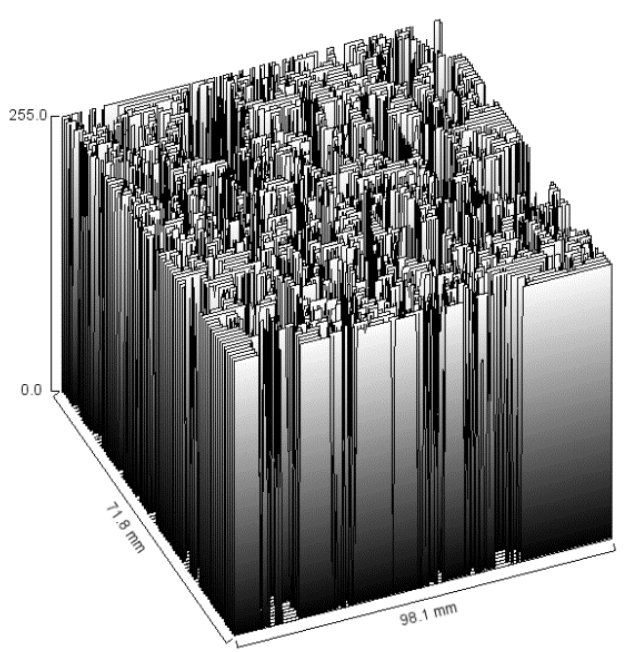

Figure 12. Surface Plot for Porous Asphalt Sample that Containing 50\% of Seashell as Aggregate Replacement

\section{Theoretical VFA and ImageJ VFA}

Figure 13 shows the comparison between theoretical VFA and ImageJ VFA (generated from ImageJ software) at different percentage of seashell, where the trend for both data is $60 \%$ the same. Theoretical VFA for the porous asphalt sample that containing $20 \%, 30 \%$, and $40 \%$ of seashell as aggregate replacement is lower than the ImageJ VFA. However, theoretical VFA for the porous asphalt sample that containing $10 \%$ and $50 \%$ of seashell as aggregate replacement is higher than the ImageJ VFA. This is due to the area of cut porous asphalt image that inserts in ImageJ software, where the total area of cut porous asphalt image that analyzed in ImageJ software is not exactly the same with the actual sample area.

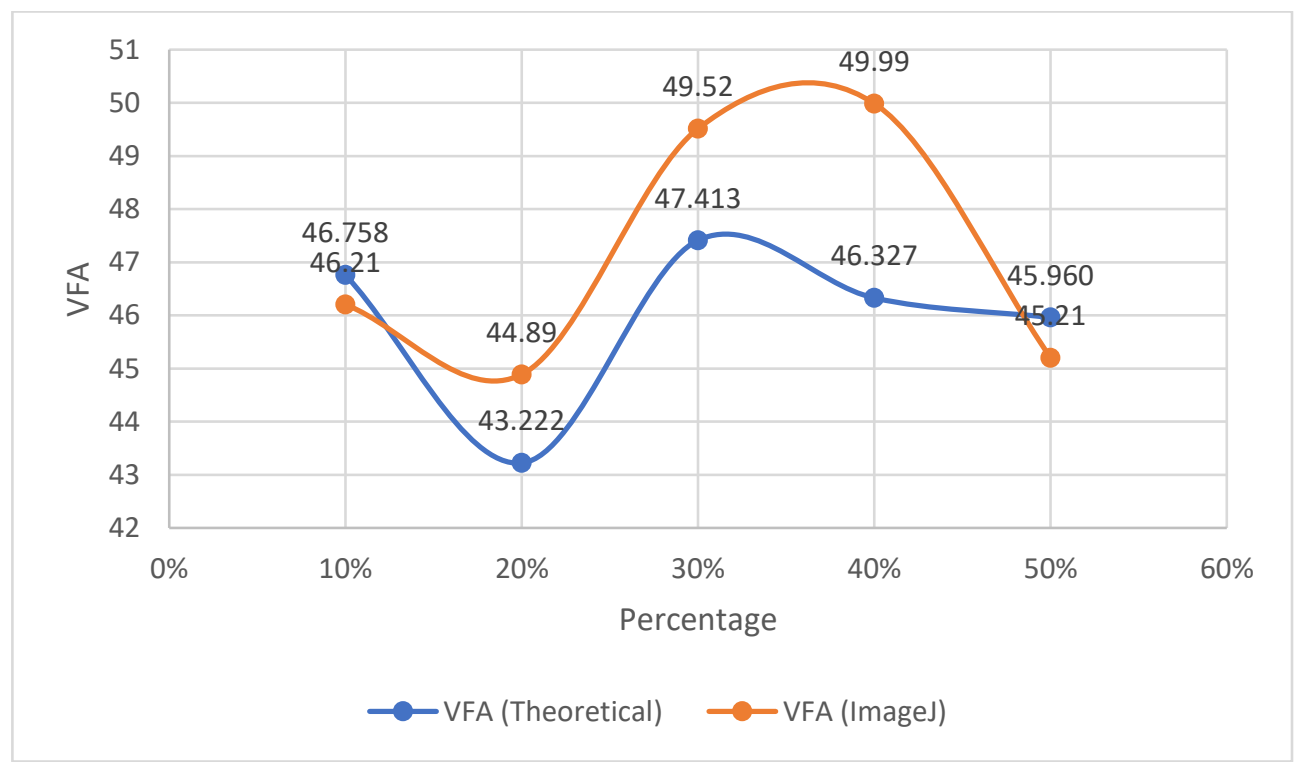

Figure 13. Comparison between Theoretical VFA and ImageJ VFA at different percentage of seashell

\section{CONCLUSION}

The porous asphalt sample that containing seashell as aggregate replacement can perform well as compared to the conventional porous asphalt. It can be proved that the porous asphalt that containing seashell as aggregate replacement shows a different result, where it had lower stability value as compared to the conventional porous asphalt. However, the bulk density of porous aspphalt sample can be increase by replacing seashell in porous asphalt sample. Furthermore, by replacing seashell in porous asphalt sample the permeability coefficient is higher as compared to the conventional porous asphalt. The surface of seashell shell able to bond with bitumen, thus, the binding between seashell and bitumen is good. Lastly, VFA and VTM value are affected by the surface and position of the seashell in the porous asphalt sample. 


\section{ACKNOWLEDGEMENT}

The support provided by Malaysian Ministry of Higher Education and Universiti Malaysia Pahang in the form of research grant PGRS2003172 is highly appreciated. Acknowledgement is also towards all the technicians of Highway and Traffic Engineering Laboratory, Universiti Malaysia Pahang, for their help. Appreciation also to seafood restaurant for supplying cockle shell.

\section{REFERENCES}

[1] Peduzzi, P. (2014). Sand, rarer than one thinks. Article reproduced from United Nations Environment Programme (UNEP) Global Environmental Alert Service (GEAS). Environmental Development, 11, 208-218. Retrieved from http://archiveouverte.unige.ch/unige:75919

[2] Mo, K. H., Alengaram, U. J., Jumaat, M. Z., Lee, S. C., Goh, W. I., \& Yuen, C. W. (2018, February 20). Recycling of seashell waste in concrete: A review. Construction and Building Materials. Elsevier Ltd. https://doi.org/10.1016/j.conbuildmat.2017.12.009

[3] Eziefula, U. G., Ezeh, J. C., \& Eziefula, B. I. (2018, December 20). Properties of seashell aggregate concrete: A review. Construction and Building Materials. Elsevier Ltd. https://doi.org/10.1016/j.conbuildmat.2018.10.096

[4] Ruiz, G., Chávez, F., Santamaría, S., Araujo, W., Timaná, J., \& Schmitt, R. (2020). Laboratory evaluation of seashells used as fine aggregate in hot mix asphalt. International Journal of Pavement Engineering, 21(5), 620-628. https://doi.org/10.1080/10298436.2018.1502435

[5] Kandhal, P. S., \& Mallick, R. B. (1998). Open-Graded Asphalt Friction Course: State of the Practice. NCAT Report 98-07, (May), 28.

[6] ASTM International. (2015). ASTM D6927 - 15: Standard Test Method for Marshall Stability and Flow of Asphalt Mixtures. Designation: D6927-15. American Society for Testing Materials, i, 1-7.

[7] ASTM PS129 2001 Standard Provisional Test Method for Measurement of Permeability of Bituminous Paving Mixtures Using a Flexible Wall Permeameter, American Society for Testing and Materials, West Conshohocken, PA, USA

[8] JKR, 2008. JKR/SPJ/2008-S4 Standard Specification for Road Works Part4 Flexible Pavement. JKR Specification for Road Works Part4 Flexible Pavement 07, 1-187.

[9] Ministry of Marine and Fisheries (MMF), 2007. Statistical of Marine and Fisheries (Jakarta).

[10] Wahyuni, A. S., Supriani, F., Elhusna, \& Gunawan, A. (2014). The performance of concrete with rice husk ash, sea shell ash and bamboo fibre addition. In Procedia Engineering (Vol. 95, pp. 473-478). Elsevier Ltd. https://doi.org/10.1016/j.proeng.2014.12.207

[11] Martínez-García, C., González-Fonteboa, B., Martínez-Abella, F., \& Carro- López, D. (2017). Performance of mussel shell as aggregate in plain concrete. Construction and Building Materials, 139, 570-583. https://doi.org/10.1016/j.conbuildmat.2016.09.091

[12] Olivia, M., Oktaviani, R., \& Ismeddiyanto. (2017). Properties of Concrete Containing Ground Waste Cockle and Clam Seashells. In Procedia Engineering (Vol. 171, pp. 658-663). Elsevier Ltd. https://doi.org/10.1016/j.proeng.2017.01.404

[13] Tayeh, B. A., Hasaniyah, M. W., Zeyad, A. M., \& Yusuf, M. O. (2019, November 10). Properties of concrete containing recycled seashells as cement partial replacement: A review. Journal of Cleaner Production. Elsevier Ltd. https://doi.org/10.1016/j.jclepro.2019.117723

[14] Vijaya Ramnath, B., Jeykrishnan, J., Ramakrishnan, G., Barath, B., Ejoelavendhan, E., \& Arun Raghav, P. (2018). Sea Shells and Natural Fibres Composites: A Review. In Materials Today: Proceedings (Vol. 5, pp. 1846-1851). Elsevier Ltd. https://doi.org/10.1016/j.matpr.2017.11.284

[15] Zhang, Y., Chen, D., Liang, Y., Qu, K., Lu, K., Chen, S., \& Kong, M. (2020). Study on engineering properties of foam concrete containing waste seashell. Construction and Building Materials, 260. https://doi.org/10.1016/j.conbuildmat.2020.119896

[16] Khankhaje, E., Rafieizonooz, M., Salim, M. R., Mirza, J., Salmiati, \& Hussin, M. W. (2017). Comparing the effects of oil palm kernel shell and cockle shell on properties of pervious concrete pavement. International Journal of Pavement Research and Technology, 10(5), 383-392. https://doi.org/10.1016/j.ijprt.2017.05.003

[17] Muthusamy, K., Tukimat, N., Sarbini, N. N., \& Zamri, N. (2016). Exploratory study on the use of crushed cockle shell as partial sand replacement in concrete. International Journal of Research in Engineering and Science (IJRES) ISSN, 4(2), 6771. Retrieved from www.ijres.org

[18] Tarmuzi, N. A., Jaya, R. P., Yaacob, H., Hassan, N. A., \& Aziz, M. M. A. (2015). Aggregate angularity effect on porous asphalt engineering properties and performance. Jurnal Teknologi, 73(4), 99-104. https://doi.org/10.11113/jt.v73.4301

[19] Hassan, N. A., Mahmud, M. Z. H., Ahmad, K. A., Hainin, M. R., Jaya, R. P., \& Mashros, N. (2016). Air voids characterisation and permeability of porous asphalt gradations used in different countries. ARPN Journal of Engineering and Applied Sciences, 11(24), 14043-14047.

[20] Tarasco, M., Cordelières, F. P., Cancela, M. L., \& Laizé, V. (2020). ZFBONE: An ImageJ toolset for semi-automatic analysis of zebrafish bone structures. Bone, 138. https://doi.org/10.1016/j.bone.2020.115480

[21] Cong, L., Shi, J., Wang, T., Yang, F., \& Zhu, T. (2019). A method to evaluate the segregation of compacted asphalt pavement by processing the images of paved asphalt mixture. Construction and Building Materials, 224, 622-629. https://doi.org/10.1016/j.conbuildmat.2019.07.041 
[22] Xing, C., Xu, H., Tan, Y., Liu, X., Zhou, C., \& Scarpas, T. (2019). Gradation measurement of asphalt mixture by X-Ray CT images and digital image processing methods. Measurement: Journal of the International Measurement Confederation, 132, 377-386. https://doi.org/10.1016/j.measurement.2018.09.066

[23] Joohari, M. I., Aziz, N. A., Daud, N. M., Mansor, S., \& Abdul Halim, M. A. (2019). Performance of porous asphalt pavement using clay brick dust as mineral filler. In Journal of Physics: Conference Series (Vol. 1349). Institute of Physics Publishing. https://doi.org/10.1088/1742-6596/1349/1/012098

[24] Norhafizah, M., Ramadhansyah, P. J., Siti Nur Amiera, J., Nurfatin Aqeela, M., Norhidayah, A. H., Hainin, M. R., \& Che Norazman, C. W. (2016). The effect of coconut shell on engineering properties of porous asphalt mixture. Jurnal Teknologi, 78(7-2), 127-132. https://doi.org/10.11113/jt.v78.9507

[25] Aman, M. Y., Shahadan, Z., \& Tamin, N. R. M. (2015). A comparative study on properties of malaysian porous asphalt mixes with different bitumen contents. Research Journal of Applied Sciences, Engineering and Technology, 9(10), 797-806. https://doi.org/10.19026/rjaset.9.2581

[26] Mohd Satar, M. K. I., Jaya, R. P., Rafsanjani, M. H., Che Mat, N., Hainin, M. R., Aziz, M. M. A., ... Jayanti, D. S. (2018). Performance of Kaolin Clay on Hot-mix Asphalt Properties. In Journal of Physics: Conference Series (Vol. 1049). Institute of Physics Publishing. https://doi.org/10.1088/1742-6596/1049/1/012002 